\title{
Corner Cut Wide Band Microstrip Patch Antenna for Biomedical Applications
}

\author{
D. D. Ahire \\ Assistant Professor \\ Matoshri College of Engineering and Research \\ Centre, Nashik \\ Savitribai Phule Pune University, \\ Pune
}

\author{
G. K. Kharate \\ Professor \\ Matoshri College of Engineering and Research \\ Centre, Nashik \\ Savitribai Phule Pune University, \\ Pune
}

\begin{abstract}
In this research work a square corner cut rectangular wide band microstrip patch antenna is presented. A FR4 substrate is used to design a reference antenna of size $28 \times 37 \mathrm{~mm}^{2}$ with partial ground structure feed using microstrip line and results are observed for impedance bandwidth, radiation patterns and antenna gain with the help of CADFEKO, proposed wide band antenna which is design on the FR4 substrate with Partial ground structure and square notch at the lower corners on radiating patch. Results are observed from simulated design and presented current distribution for the same. Simulated impedance band width is $4.21 \mathrm{GHz}$ ( $2.99 \mathrm{GHz}-$ $7.2 \mathrm{GHz}$ ). Gain is up to $2.049 \mathrm{dBi}$. Improvement in design antenna is studied, comparison carried out between these designs. Proposed antenna VSWR bandwidth enhance from $31.8 \mathrm{GHz}$ to $4.21 \mathrm{GHz}$.
\end{abstract}

\section{Keywords}

Microstrip Line; Partial Ground; Square Notch; Wide Band; VSWR bandwidth

\section{INTRODUCTION}

Today's Wireless Technology needs a contender which fulfills need of compactness, simply fit with microwave circuits to make systems portable \& multiband operations with wide bandwidth. In recent times most of the biomedical applications wants wide bandwidth Microstrip Patch Antenna. Enormous research is going on to achieve Wideband designs. FCC defines UWB band which is suitable for biomedical application from $3.1 \mathrm{GHz}$ to $10.6 \mathrm{GHz}$.

Microstrip Patch Antenna is a major device which plays very important role in Ultra-Wideband (UWB) system, UltraWideband Technology is in its initial stage, with a huge competency. This technology shows a notable mark of capability and have a major strength in the wireless communication in upcoming years. UWB can be used in biomedical applications. Microwave imaging is one of the biomedical application, which is used to detect Breast cancer in its primary stage. Many research groups proposed techniques to achieve wide band performance, embedding Metamaterial, introducing various shapes slots, shorting pin, defective ground structure, CPW feed. Metamaterial technology is used to miniaturize antenna and also enhance efficiency of antenna. Slotting technique is introducing to match desire impedance and enhance bandwidth of micro strip patch antenna. U slot, $\mathrm{T}$ slot shapes have been presented $P$ shape slot incorporated to design a UWB device to be used for Microwave imaging technology Matching have been achieved by selecting wide slot on patch. To improved broader bandwidth by using RT Duroid substrate. [1]-[5].
Latest advance wireless communication needs compact and mobile devices with multiband operation capability antennas. All needs are completed by microstrip patch antennas which are suitable for microwave integrated circuits. These antennas have few limitations to fulfill these requirements that is of less bandwidth and gain. Research have been undertaking to achieve the bandwidth and gain. Now a days slotting technique widely used to attain multiresonant wideband performance. Other methods such as shorting pin, meandering, stacking or use of high thickness substrates have been implemented to overcome the limitations of microstrip antenna. Embedding metamaterial to achieve compact design and use of high thickness material to enhance bandwidth. [6][18].

Analysis have been carried out to find impedance of slot loaded microstrip patch antenna [19]-[22]

\section{RECTANGULAR MICROSTRIP PATCH ANTENNA DESIGN}

Antennal is a reference rectangular antenna, geometry structure shown in Fig.1 The antenna structure is designed on $1.6 \mathrm{~mm}$ thick FR4 substrate having $\mathrm{er}$ of 4.4 using approximate transmission line equations [21]-[22].

Calculated dimension of rectangular microstrip patch antenna is $\mathrm{Lp}=28 \mathrm{~mm}, \mathrm{Wp}=37 \mathrm{~mm}$. Antenna is fed through microstrip line with $3 \mathrm{~mm} \times 30 \mathrm{~mm}$ with full partial ground structure.

Antenna 1 geometry has partial ground structure $(28 \mathrm{~mm} \times 70 \mathrm{~mm})$ and square notches are introduced at lower corner of radiating patch with dimension of $(5 \mathrm{~mm} \times 5 \mathrm{~mm})$. This structure resonates at $3.18 \mathrm{GHz}$, it has been observed that square notch is changes current length and tune to single resonating frequency. Multi resonating structure tunes to single frequency when square notch is etched out on radiating patch. VSWR bandwidth is observed to be $2.97 \mathrm{GHz}(1.59 \mathrm{GHz}-4.56 \mathrm{GHz})$ with gain of $1.40 \mathrm{dBi}$

Microstrip feed line is design to match impedance with microstrip patch. Analysis of feed line is carried out using L and $\mathrm{C}$ values and find out frequency of feed line.

Dimensions of Geometry

1 Width of Substrate,

2 Length of Substrate

3 Width of Ground,

5 Width of Patch, 4 Height of Substrate

7 Length of Patch, 8 Length of Feed 

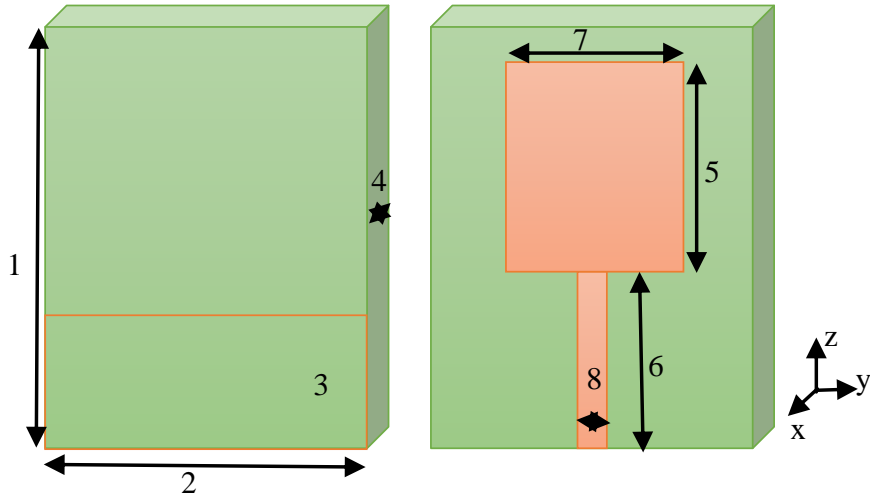

Fig 1: (a) Partial Ground Structure

(b) Radiating Patch

Antenna 2 geometry is modifying by introducing square notch to upper corners of ground with dimension of $(5 \mathrm{~mm} \times 5 \mathrm{~mm})$ resonates at $2.59 \mathrm{GHz}$ further improvement in VSWR bandwidth is observed is of $3.29 \mathrm{GHz}(1.63 \mathrm{GHz}-4.92 \mathrm{GHz})$ with gain of $2.35 \mathrm{dBi}$
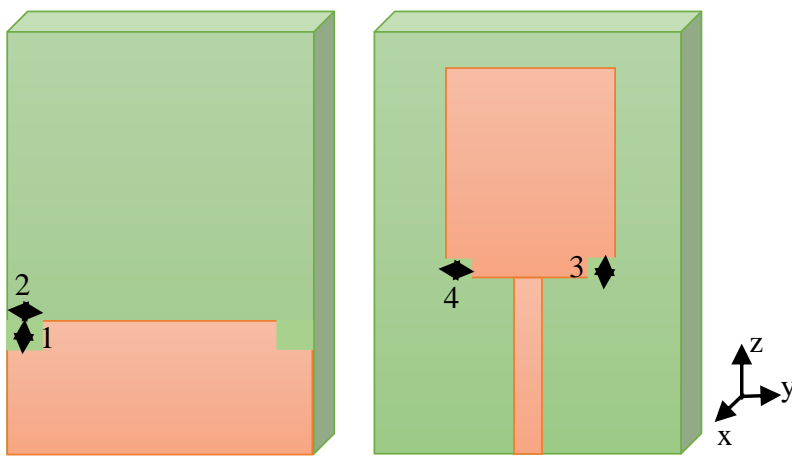

Fig.2(a) Notch cut ground structure(b)Notch cut radiating patch

1 Width of ground slot,

2 Length of ground slot 3 Width of patch slot,

4 Length of patch slot

Antenna 3 geometry is modifying by introducing square notch to upper corners of ground with dimension of $(5 \mathrm{~mm} \times 5 \mathrm{~mm})$ resonates at $6.25 \mathrm{GHz}$ further improvement in VSWR bandwidth is observed is of $4.21 \mathrm{GHz}(2.99 \mathrm{GHz}-7.2 \mathrm{GHz})$ with gain of $2.049 \mathrm{dBi}$
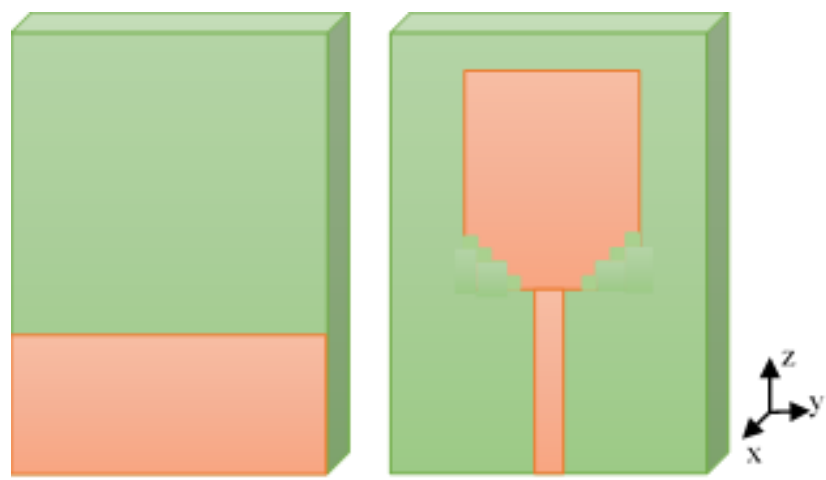

Fig.3(a) Partial Ground Structure (b)Notch cut Radiating Patch

With this structure VSWR bandwidth is improved up to $4.21 \mathrm{GHz}$ from multiband resonating antenna to single tuned wide band design. To enhance the performance of antenna square notch on radiating patch well use of partial ground structure. lower corners of patch etched out in square shape shows enhancement of VSWR bandwidth.
Radiation pattern of proposed antenna shows $\mathrm{E}$ plane and $\mathrm{H}$ Plane field. E filed pattern shows effect of notches etched out on patch as compared to antenna 1 and antenna 2

\section{SIMULATED RESULTS}

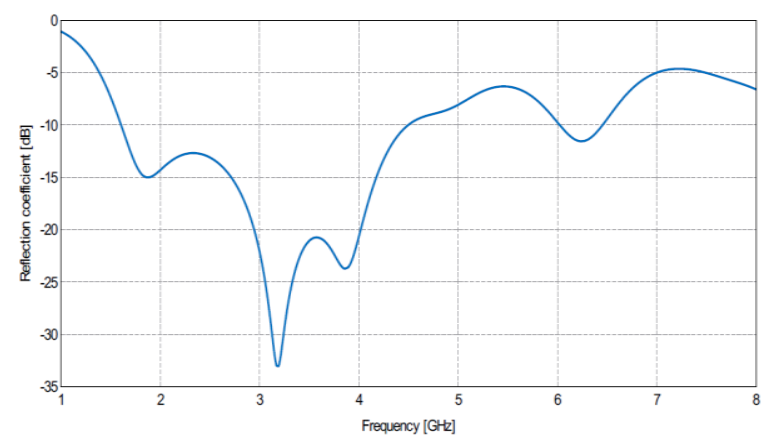

Fig 4: Simulated Reflection coefficient of Antenna1

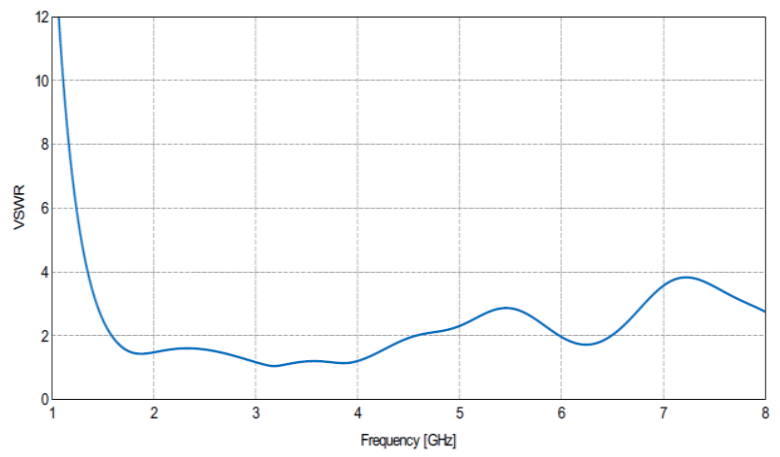

Fig 5: Simulated VSWR Band width of Antenna1

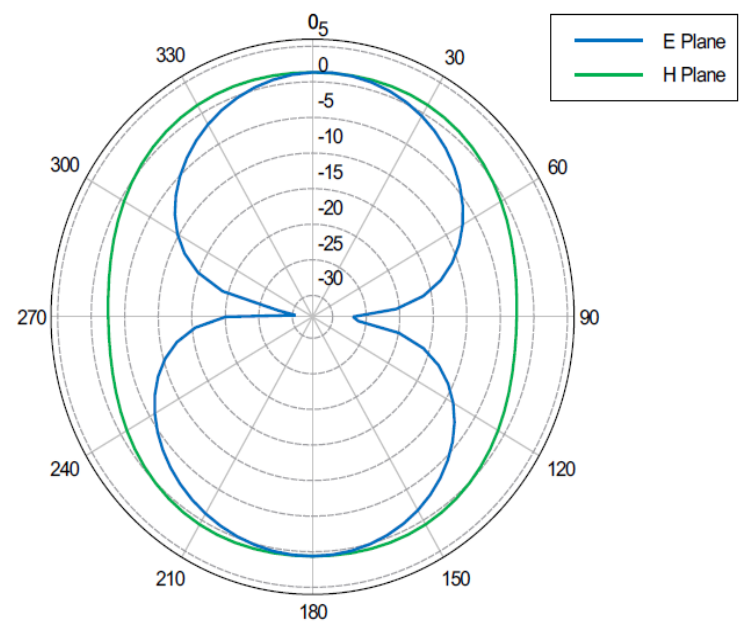

Fig 6. Simulated result of Radiation Pattern of Antenna 1 


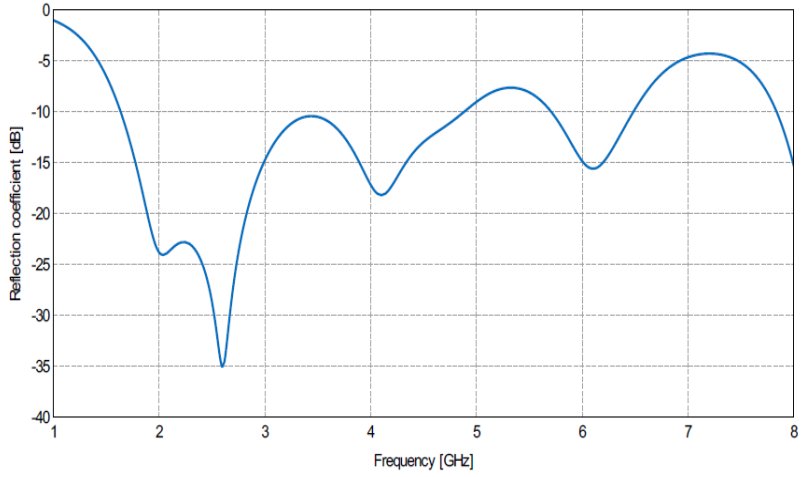

Fig 3: Simulated Reflection Coefficient of Reference Antenna2

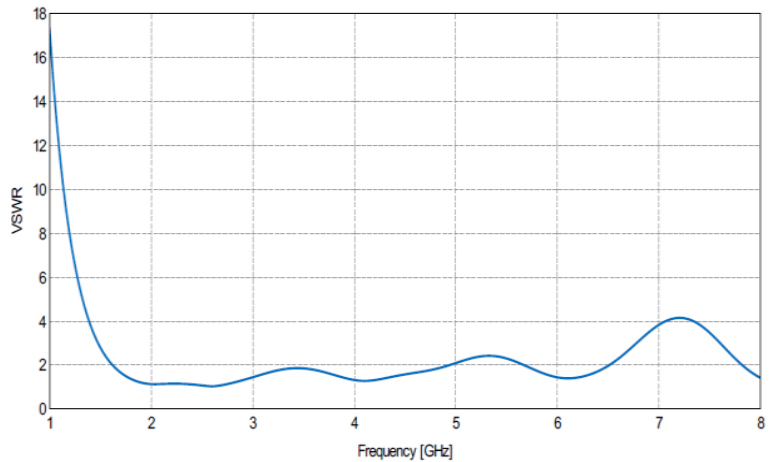

Fig 7: Simulated VSWR Band width of Antenna2

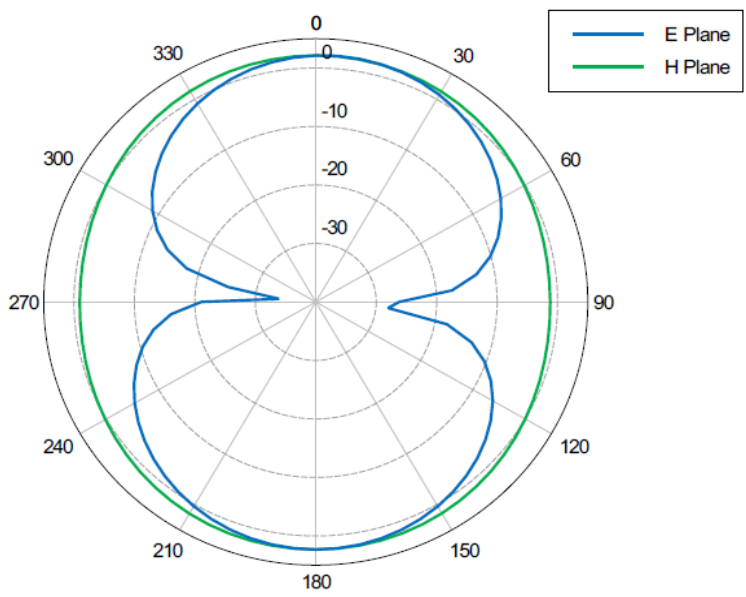

Fig 8. Simulated result of Radiation Pattern of Antenna 2

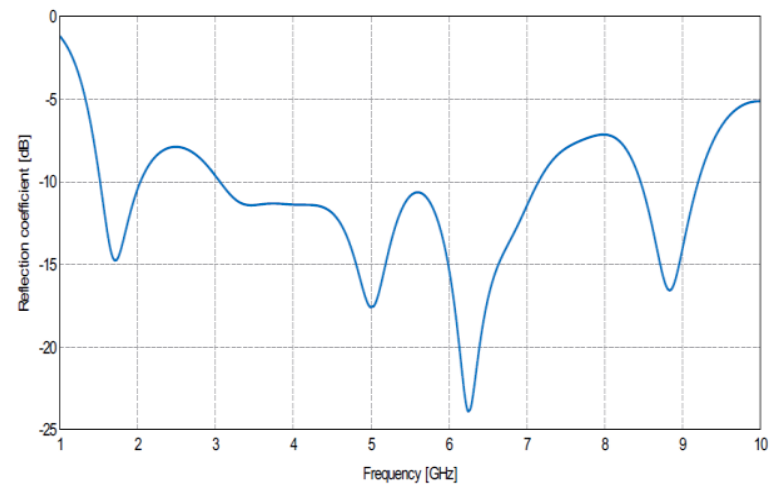

Fig 9: Simulated Reflection coefficient of Antenna3

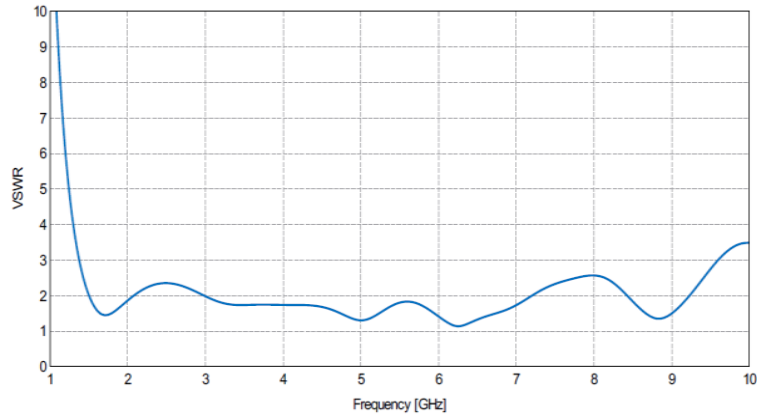

Fig 10: Simulated VSWR band width of Antenna3

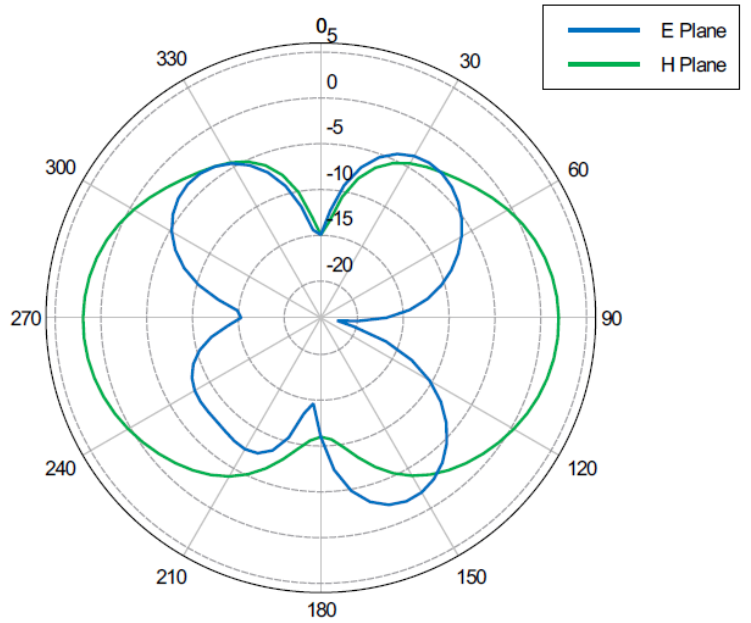

Fig 11. Simulated result of Radiation Pattern of Antenna 3

\section{DESIGN EQUATION}

$$
\begin{aligned}
& C_{1}=\frac{L W \varepsilon_{0} \varepsilon_{e}}{2 H} \cos ^{2}\left(\left[\frac{\pi X_{0}}{L}\right]\right)-i \\
& R_{1}=\frac{Q}{C_{1} \omega_{r}^{2}}-i i \\
& L_{1}=\frac{1}{C_{1} \omega_{r}^{2}}-i i i \\
& Q=\frac{c \sqrt{\varepsilon_{e}}}{4 f H}-i v
\end{aligned}
$$

where:

$\mathrm{L} \quad=$ Length of rectangular patch

$\mathrm{W} \quad=$ Width of rectangular patch

$\mathrm{X}_{0} \quad=\mathrm{y}$ coordinate of feed point

$\mathrm{H} \quad=$ Thickness of the substrate material

$\varepsilon_{\mathrm{e}} \quad=$ effective permittivity of the medium

Microstrip Line

$L_{L}=100 . H\left(4 \sqrt{W_{s} / H}-4.21\right) \mathrm{nH}-v$

$C_{L}=W_{s}\left\{\left(9.5 \varepsilon_{r}+1.25\right) W_{s} / H+5.2 \varepsilon_{r}+7.0\right\} p F-v i$

Resonance frequency of transmission line is given by

$f=c / 2 L_{e} \sqrt{\varepsilon_{r e}}-v i i$

These equations use to design microstrip patch, feed line equations are also used to design feed line. 


\subsection{Parametric Study}

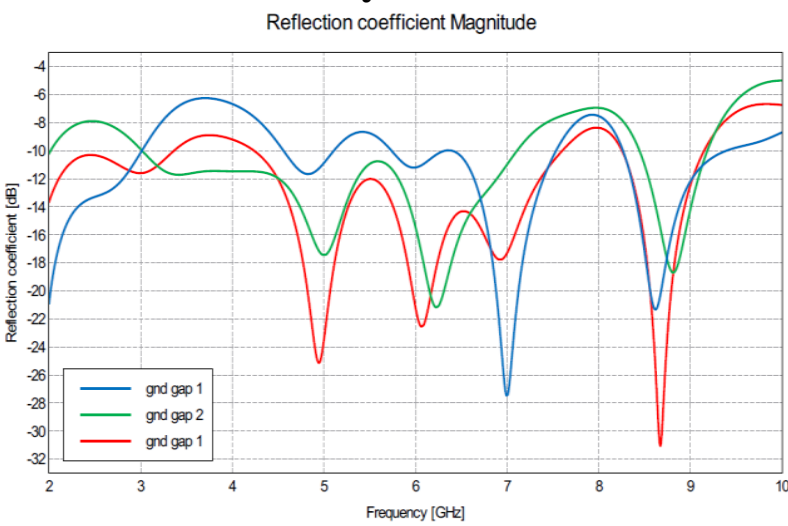

Fig 12. Reflection Coefficient graph for different ground and patch gap

Table 1 Ground Gap Effect

\begin{tabular}{|c|c|c|c|}
\hline $\begin{array}{l}\text { Ground } \\
\text { GaP } \\
(\mathrm{mm})\end{array}$ & B.W & $\begin{array}{c}\text { Resonant } \\
\text { Frequency }\end{array}$ & $\begin{array}{l}\text { Reflection } \\
\text { coefficient(dB) }\end{array}$ \\
\hline \multirow{3}{*}{1} & 3.34 & 4.94 & -25.13 \\
\cline { 2 - 4 } & 0.896 & 8.67 & -31.09 \\
\hline \multirow{2}{*}{2} & 4.21 & 6.25 & -21.18 \\
\cline { 2 - 4 } & 0.730 & 8.81 & -18.69 \\
\hline \multirow{2}{*}{0} & 1.13 & 6.998 & -27.33 \\
\cline { 2 - 4 } & 1.12 & 8.63 & -21.3 \\
\hline
\end{tabular}

Parametric study observes gap between partial ground and patch of antenna 3, effect on bandwidth of design. Partial ground mainly used to match impedance. Ground width changes which reduces gap between patch and partial ground. Optimized dimensions give good result of proposed design.

\subsection{Current Distribution}

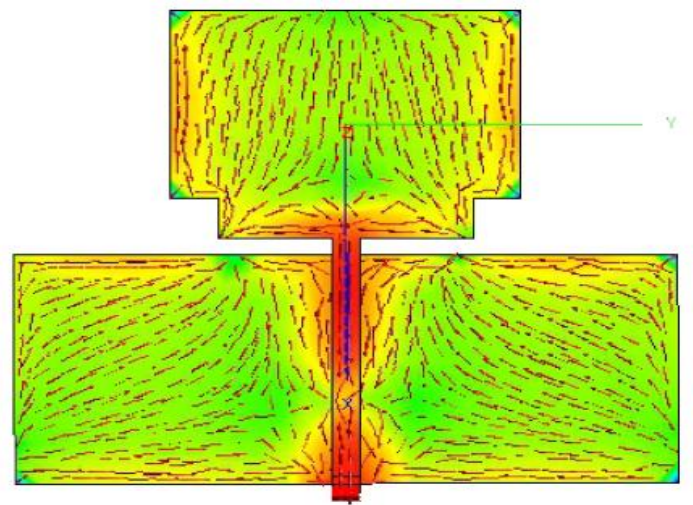

Fig.13 Current Distribution of Proposed wide band Antenna 1

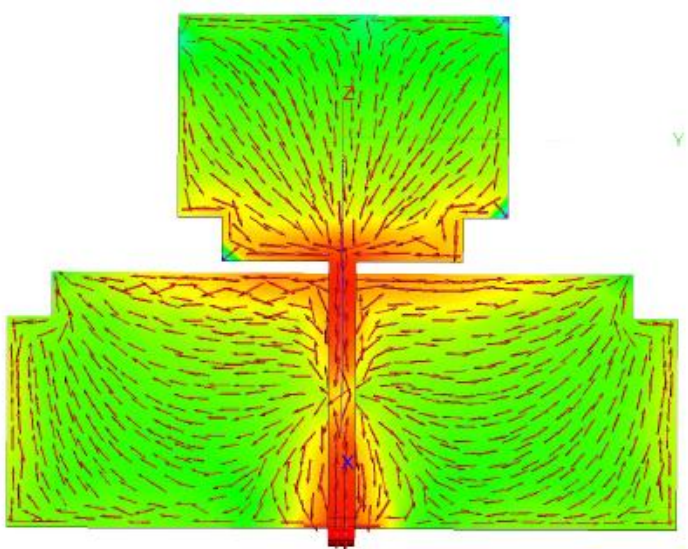

Fig.14 Current Distribution of Proposed wide band Antenna 2

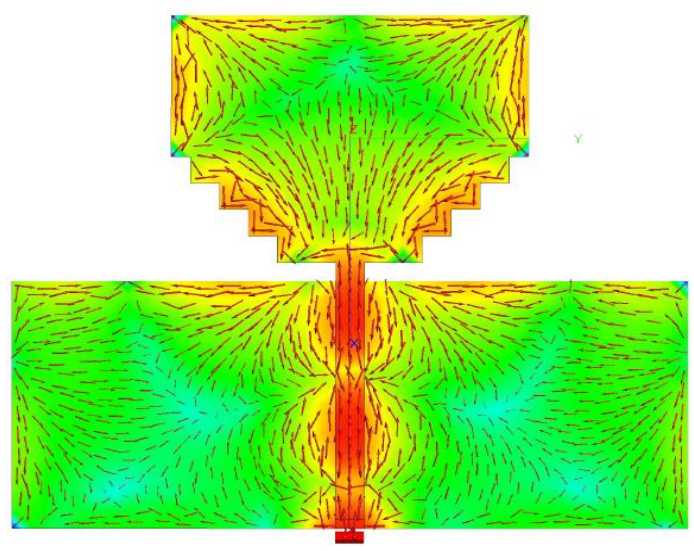

Fig.15 Current Distribution of Proposed wide band Antenna 3

The simulated far field radiation pattern of Antenna 1, Antenna 2 and Antenna 3 shown in Fig.6, Fig.8 and Fig. 11 in $\mathrm{E}$ plane and $\mathrm{H}$ plane resonating at $3.18 \mathrm{GHz}, 2.59 \mathrm{GHz}$ and $6.25 \mathrm{GHz}$ Radiation performance of design antenna1, antenna 2 and antenna 3 is studied by surface current distribution at Centre frequency of $3.18 \mathrm{GHz}, 2.59 \mathrm{GHz}$ and $6.25 \mathrm{GHz}$. Current in first two designs is linear and proposed antenna with square cut notch changes current direction helps to be a wide band design. Designed antenna shows good matching between microstrip feed line and patch to deliver maximum power to patch.

\section{RESULTS AND DISCUSSION}

Table 2: Comparison of simulated designs

\begin{tabular}{|c|c|c|c|}
\hline $\begin{array}{c}\text { Antenn } \\
\mathrm{a}\end{array}$ & $\begin{array}{c}\text { Resonance } \\
\text { Frequency } \\
(\mathrm{GHZ})\end{array}$ & $\begin{array}{c}\text { VSWR } \\
\text { B.W(GHz) }\end{array}$ & $\begin{array}{c}\text { Gain } \\
(\mathrm{dBi})\end{array}$ \\
\hline 1 & 3.18 & 2.97 & 1.40 \\
\hline 2 & 2.59 & 3.29 & 2.35 \\
\hline 3 & 6.25 & 4.21 & 2.049 \\
\hline
\end{tabular}

Proposed design structure resonates to frequency range from $2.99 \mathrm{GHz}$ to $7.2 \mathrm{GHz}$ with VSWR <2 with good impedance matching.

\subsection{Conclusion}

Corner cut microstrip line feed wideband patch antenna with partial ground structure is presented. The simulated results show that the proposed design gives VSWR band width of 
$4.21 \mathrm{GHz}(2.99 \mathrm{GHz}-7.2 \mathrm{GHz})$ with gain of $2.0049 \mathrm{dBi}$. Which comes in Ultra-Wide Band $(3.1 \mathrm{GHz}-10.6 \mathrm{GHz})$. It is observed that by cutting square notch to lower corners of radiating patch improvement in bandwidth by $1.03 \mathrm{GHz}$ as compared to reference antenna. This proposed structure is suitable for biomedical applications. This antenna can be further use to design UWB system by using slotting and shorting pin technique to detect malignant tumors in breast at infancy. This will be the focus of further research

\section{REFERENCES}

[1] J.G. Joshi, Shyam S. Pattnaik*, and S. Devi, "Rectangular Slotted Microstrip Patch Antenna with Partially Loaded Metamaterial Ground Plane", International Journal of Microwave And Optical Technology, Vol. 8, No.1, January 2013

[2] J. A. Ansari, and R.B.Ram, "Broadband Stacked U-Slot Microstrip Patch Antenna," Progress in Electromagnetics Research Letters, Vol. 4, pp. 17-24, 2008.

[3] Ashish Singh, J.A Ansari, Mohd Aneesh, Saiyed Salim Sayeed, A Mishra, "Analysis of slots and notches loaded patch antenna for dual band operation", Multimedia, Signal Processing and Communication Technologies (IMPACT), 2013 International Conference.

[4] D.D.Ahire, G.K.Kharate, "Dual Band Microstrip Patch Antenna for Wireless Applications", I J C T A,10(8),2017 pp. 167-175 ISSN: 09745572,International Science Press

[5] S. S. Tiang, M. F. Ain, and M. Z. Abdullah," MicrostripFed Low Profile and Wideband Wide-Slot Antenna for Breast Imaging", Proceedings of APMC 2012, Kaohsiung, Taiwan, Dec. 4-7, 2012

[6] U. Chakraborty, A. Kundu, S.K. Chowdhury, and A.K. Bhattacharjee, "Compact Dual-Band Microstrip Antenna for IEEE 802.11a WLAN Application", IEEE Antenna and Wireless Propagation Letters, Vol. 13, pp. 407-410, 2014.

[7] J.G. Joshi, Shyam S. Pattnaik*, and S. Devi, "Geo-textile Based Metamaterial Loaded Wearable Microstrip Patch Antenna",International Journal of Microwave And Optical Technology, Vol. 8, No.1, January 2013.

[8] J.G.Joshi, Shyam S. Pattnaik*, and S. Devi, "Rectangular Slotted Microstrip Patch Antenna with Partially Loaded Metamaterial Ground Plane", International Journal of Microwave And Optical Technology, Vol. 8, No.1, January 2013
[9] Y.P.Zhang, "Design and Experiment on Differentially Driven Microstrip Antennas", IEEE transaction on antenna and wireless prorogation letters, vol. 55, No. 10, pp. 2701-2708, October 2007

[10] Y.P.Zhang, "Design and Experiment on Differentially Driven Microstrip Antennas", IEEE transaction on antenna and wireless prorogation letters, vol. 55, No. 10, pp. 2701-2708, October 2007.

[11] A.A.Deshmukh, and K.P.Ray, "Compact Broadband Slotted Rectangular Microstrip Antenna," IEEE Antennas and Wireless Propagation Letters, Vol. 8, pp. 1410-1413, 2009.

[12] A. Mishra, P. Singh, N.P.Yadav, and J.A. Ansari, "Compact Shorted Microstrip Patch Antenna for Dual Band Operation," Progress in Electromagnetics Research C, Vol. 9, pp. 171-182, 2009.

[13] J.Y.Sze, and K.L.Wong, "Slotted Rectangular Microstrip Antenna for Bandwidth Enhancement,"IEEE Transaction on Antenna and Wireless Prorogation Letters, Vol.48, pp.1149-1152, August 2000

[14] Xiao Lei Sun, L.Lui, S.W. Cheung, and T.I.Yuk, "Dual Band Antenna with Compact Radiator for 2.4/5.2/5.8 GHz WLAN Application," IEEE Transaction Antennas Propagation, Vol. 60, No. 12, pp. 5924-5931, Dec 2012.

[15] M.T.Islam, "Multi Slotted Microstrip Patch Antenna for Wireless Communication, "Progress in Electromagnetics Research Letters, Vol. 10, pp. 11-18, 2009.

[16] S. Sharma, and B.R.Vishvakarma, "Analysis of Slot Loaded Microstrip Patch Antenna," Indian Journal of Radio and Space Physics, Vol. 3, pp. 424-430, December 2005.

[17] J.A.Ansari and Sapna Verma, "Analysis of T-Slot Loaded Disk Patch Antenna for Dual Band Operation with Small Frequency Ratio", International Journal of Future Generation Communication and Networking, Vol8,No.3(2015)

[18] K.L.Wong, and W.H. Hsu, “A Broad Band Rectangular Patch Antenna with a Pair of Wide Slits, "IEEE Transactions on Antennas and Propogation,Vol. 49, No. 9, pp. 1345-1347, September 2001

[19] .R. Garg "Microstrip patch antenna design handbook, Artech House," 2001.

[20] Constantine A. Balanis ; Antenna Theory, Analysis and Design, John Wiley \& Sons Inc 2nd edition 1997. 